\title{
Gürsu, Uğur (2020). Tuhfe-i Sabrî an Lisân-ı Bulgarî, İstanbul: Akademi Titiz Yay., ISBN: 978-605-7604-20-0
}

\author{
Zeynep Negiş ${ }^{1}$ (1)
}

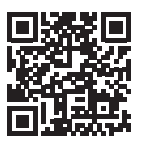

'Öğretim Görevlisi, İstanbul Üniversitesi, Edebiyat Fakültesi, İstanbul, Türkiye

ORCID: Z.N. 0000-0002-4477-0731

Sorumlu yazar/Corresponding author: Zeynep Negiş,

Öğretim Görevlisi, İstanbul Üniversitesi, Edebiyat Fakültesi, İstanbul, Türkiye

E-mail: zeynep.sertbas@istanbul.edu.tr

Başvuru/Submitted: 12.09 .2020

Kabul/Accepted: 09.12.2020

\section{Atuf/Citation:}

Negis, Z. (2020). Gürsu, Uğur (2020). Tuhfe-i Sabrî an Lisân-l Bulgarî [Uğur Gürsu tarafindan yayına hazırlanan Tuhfe-i Sabrî an Lisân-l Bulgarî başlıklı kitabın değerlendirmesi]. TUDED 60(2), 815-818.

https://doi.org/10.26650/TUDED2020-0055

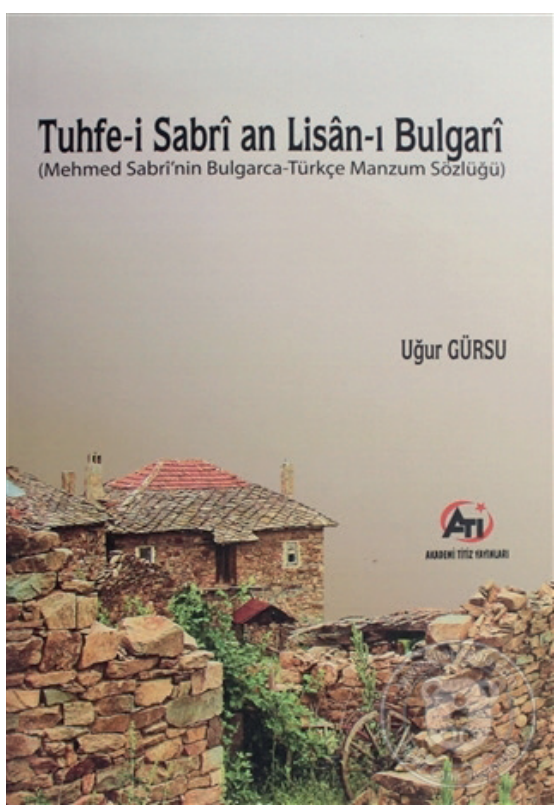


Türk sözlükçülük tarihinde 11. yüzyılda kaleme alınan Dîvânu Lugât'it-Türk'ten bu yana Arapça-Türkçe, Farsça-Türkçe, Moğolca-Türkçe, Boşnakça-Türkçe, Fransızca-Türkçe gibi pek çok dilde sözlükler hazırlandığı görülür. Bu sözlüklerin büyük çoğunluğu mensur eserlerdir. Bunun yanında sözlükçülük geleneğimizde "tuhfe" adı verilen manzum sözlüklerin bulunduğu bilinmektedir. Arapça bir kelime olan tuhfe, "hediye, güzel şey” anlamındadır. Terim olarak ise kelime birden fazla dilli sözlüklerde sözcük karşılıklarının şiir şeklinde verildiği sözlüklere verilen addır (Akalın, 2010:167). Bu tarz sözlüklerde bilimsellikten ziyade fayda ön plandadır. Genellikle çocukların yabancı kelimeleri rahat ezberleyebilmelerini sağlamanın yanında aruz veznini öğretme gibi işlevleri de vardır (Kılıç, 2007, s. 12). Bu sözlüklerin çoğunluğu ArapçaTürkçe ve Farsça-Türkçe ise de Boşnakça-Türkçe, Rumca-Türkçe, Fransızca-Türkçe gibi farklı dillerde yazılmış tuhfeler de vardır.

Manzum sözlük geleneğinin Bulgarca-Türkçe olarak yazılmış tek örneği olan Mehmed Sabrî'nin Tuhfe-i Sabrî an Lisân-ı Bulgarî adlı eseri, daha önce de Lügat-i Bulgarîve Zübdetü'lHâşi'în, Rusça-Türkçe Sözlük gibi 19. yüzyılda yazılmış sözlükler üzerine çalışmaları olan Uğur Gürsu tarafından hazırlanarak Şubat 2020 tarihinde Akademi Titiz Yayınları tarafından yayımland1.

Toplam 234 sayfa olan çalışma "İçindekiler”, “Önsöz”, "Eserin Yazarı”, “Eserin Şekil ve İçerik Özellikleri”, "Eserin İmla Özellikleri”, "Kısaltma ve Semboller Listesi”, “Transkripsiyonlu Metin”, “Orijinal Metin”, “Sözlük-Dizin” ve “Kaynakça” bölümlerinden oluşmaktadır.

“Giriş” bölümünde Uğur Gürsu, tuhfe kelimesini açıklayarak tuhfe türü sözlüklerin Arap edebiyatında ortaya çıkışı ve Türk edebiyatındaki yeri hakkında bilgiler vermektedir. Eserin "Yazarı" bölümünde ise hakkında neredeyse hiçbir bilgi bulunmayan yazara ait tek belge olan bir muvakkat ruhsatname, orijinal belge olarak transkripsiyonu ile paylaşılmakta ve bu yazar hakkında farklı araştırmacıların yorumları üzerinde durulmaktadır.

“Şekil ve İçerik Özellikleri” bölümünde Gürsu eser hakkında şu bilgileri verir:

Hicri 1296, miladî 1879 yılında basılan Tuhfe-i Sabrî Lisân-ı Bulgarî 44 sayfadan oluşan bir Bulgarca-Türkçe sözlüktür. Sözlüğün 2. sayfasının 3. satırından itibaren her satırında genellikle 3 Bulgarca kelimenin Türkçe karşılıkları verilmiştir... Sözlüğün 2. ve 42. sayfaları arasında kalan kısmında (her misrada 3 kelime ve her sayfada 16 mısra olmak üzere) yaklaşık 1800 Bulgarca kelime ve bunların Türkçe karşılıkları yer almaktadır. (s. 13) 


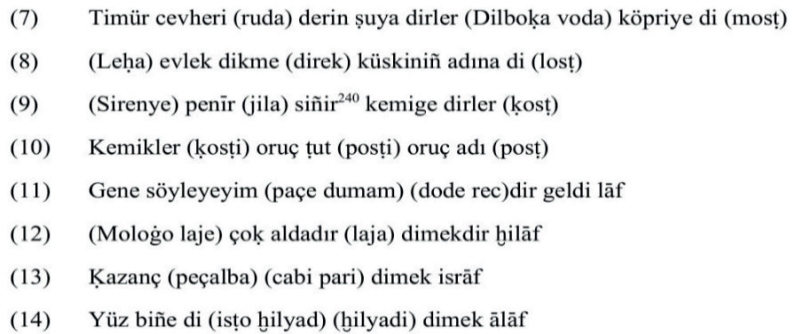

Bu bölümde ayrıca çalışılan eserde giriş kısmının olmaması üzerinde durularak bunun nedenleri üzerinde bir değerlendirme yapan Gürsu, dönemin siyasi ortamının esere yansımış olabileceği değerlendirmesinde bulunur. Ardından sözlükte tercih edilen kelime türleri ve bu kelimelerin ne şekilde değerlendirildiklerinden bahsedilir. Bu kelimelerin dizilişlerinde alfabetik sıra ya da konularına göre bir tasnif gözetilmemişse de benzer konulardaki kelimelerin bir arada verilmeye çalışıldığı görülür. Bu bölümü eserin aruz ve kafiye incelemesi takip etmektedir. Çalışmada Uğur Gürsu, sözlük yazarı Mehmed Sabrî’nin vezin ve kafiye kullanımı ile diğer manzum sözlük yazarlarının kullanımları arasında bir karşılaştırmada bulunmaktadır. Buna göre yazar vezin kullanımında tam bir ustalık gösteremiyorsa da kafiye kullanımında oldukça başarılıdır.

Eserin “İmla Özellikleri” bölümünde kısaca dil kullanımından bahsedildikten sonra eserde yer alan imla tutarsızlıkları, ses değişmeleri ve Bulgarca kelimelerin yazılışları üzerinde durulmuştur. Ayrıca Türkçede yer almayıp Bulgarcada bulunan seslerin durumları hakkında bilgi verilmiştir.

“Transkripsiyonlu Metin” bölümü 25-97. sayfalar arasında yer alır. Bu bölümde sözlükte yer alan Bulgarca kelimelerin tamamının Kiril harfli yazılışlarının dipnotlarla gösterilmiş olması dikkat çekmektedir.

(1) Tanrı ism-i pâkine (gospot) ${ }^{1}$ dirler afv eyle günâhım ey hudâ

(2) Dû cihânda etme rüsvây rahmetinle ${ }^{2}$ yarlıga

(3) Dayı (uyka) ${ }^{3}$ hala (lelka) ${ }^{4}$ büyük anaya (baba) ${ }^{5}$

(4) $\quad$ (Ludo) $^{6}$ mecnûn (igra) $)^{7}$ oyun düğün adı (isvadba) ${ }^{8}$

(5) $\quad$ (Brimka) ${ }^{9}$ tuzak balık ağı oldu (sak) ${ }^{10}$ balık adı (riba) $)^{11}$

(6) Salıncak (lulka) ${ }^{12}$ kaplumbağaya (jelka) ${ }^{13}$ kurbağaya de (jaba) ${ }^{14}$

(7) (Potpor) $^{15}$ dayak (topol) ${ }^{16}$ kavak söğüd adı (virba) ${ }^{17}$

(8) $\quad$ (Polovina) ${ }^{18}$ bel (raka) ${ }^{19}$ el avuç adı (şepa) ${ }^{20}$

(9) (Piremna) çamaşır potur adı (çakşir) ${ }^{21}$ kalpağa de (kapa) ${ }^{22}$

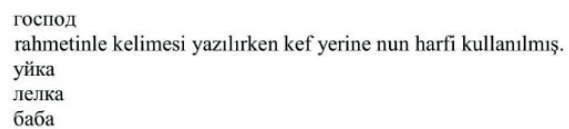


Sonuç olarak Uğur Gürsu'nun titizlikle hazırladığı Mehmed Sabrî'ye ait Tuhfe-i Sabrî an Lisân-ı Bulgarî adlı eser, 19. yüzyıl sonunda Rumeli ağzı hakkında bilgi vermesi bakımından bu alanda çalışan araştırmacılar için zengin bir veri sunmaktadır. Ayrıca gündelik konuşmaya dair kelimeler barındırması dikkat çekicidir. Köklü bir geleneğe sahip olan Balkan Türkolojisi alanında çalışanlar için faydalı bir kaynak olduğu da açıktır.

\section{KAYNAKÇA/REFERENCES}

Akalın, Ş. H. (2010). Sözcük Bilimi ve Sözlükçülük. Türk Dili Dil ve Edebiyat Dergisi, C. XCVIII, S. 698. 162-169.

Gürsu, U. (2020). Tuhfe-i Sabrî an Lisân-ı Bulgarî. İstanbul: Akademi Titiz Yayınları.

Kılıç, A. (2007). Manzum Sözlük Mecmuası (Konya Mevlânâ Müzesi Kütüphanesi 4026) Tuhfe-i Vehbí Tuhfe-i Şāhidí - Sübha-i Ŝ̉byān (İnceleme-Metin). Kayseri: Laçin Yayınları. 